\title{
Rapid ultra-performance liquid chromatography assay of losartan potassium in bulk and formulations
}

Tarab J Ahmad ${ }^{4 *}$, Amruth Raj ${ }^{1}$, Rayapura T Radhika ${ }^{2}$, Sannaiah Ananda ${ }^{3}$, Netkal M Gowda ${ }^{4}$ and Bellale M Venkatesha ${ }^{\text {* }^{*}}$

\begin{abstract}
Background: Losartan potassium is a non-peptide AT1 receptor drug used in the treatment of hypertension.

Methods: A simple, rapid, sensitive, and validated isocratic reverse-phase ultra-performance liquid chromatographic (RP-UPLC) method was developed and validated for the determination of losartan potassium (LOS) in bulk drug and tablets. The assay was developed using Waters Acquity BEH C18 (100 mm $\times 2.1 \mathrm{~mm}), 1.7-\mu \mathrm{m}$ column with a mobile phase consisting of a mixture of phosphate buffer $(\mathrm{pH} 3.2)$ and acetonitrile (50:50 v/v).

Results: An assay with a total run time of only 5 min was developed. The method monitored at $245 \mathrm{~nm}$ exhibited linearity over a concentration range of 2.0 to $15.0 \mu \mathrm{g} \mathrm{mL} \mathrm{L}^{-1} \mathrm{LOS}$. The limits of detection and quantification (signal-to-noise ratio $(S / N)=10$ ) were found be 0.018 and $0.054 \mu \mathrm{gL}^{-1}$, respectively. The intraday and interday RSDs were less than $1.0 \%$. The method was validated by the determination of LOS levels in tablets where the percentage on the label claim was $100 \pm 2$. The accuracy of the method was further ascertained by recovery studies via the standard addition procedure, which yielded satisfactory results.
\end{abstract}

Conclusion: A rapid UPLC assay of LOS in bulk drug and tablets was developed and validated.

Keywords: Losartan potassium; Ultra-performance liquid chromatography; Assay; Pharmaceutical; C-18 column

\section{Background}

Losartan potassium, a monopotassium salt of 2-butyl-4chloro-1-[ $p$-(o-1H-tetrazol-5-ylphenyl)benzyl] imidazole5 -methanol or (2-butyl-4-chloro-1-\{[2'-(1H-tetrazol-5-yl) biphenyl-4-yl]methyl\}-1 $H$-imidazol-5-yl)methanol (Figure 1), is a non-peptide AT1 receptor antagonist used for the treatment of hypertension (Conlin 2001). Losartan potassium was the first angiotensin II receptor antagonist to be marketed. Currently, it is marketed by Merck and Co. Inc. under the trade name, Cozaar. Several analytical techniques have been reported for the determination of losartan potassium (LOS) in different pharmaceutical formulations and in biological fluids. Most of these methods employ highperformance liquid chromatography (HPLC) with UV detection (Seburg et al. 2006; Pedroso et al. 2009). The drug LOS is determined by HPLC in the presence of other drugs

\footnotetext{
*Correspondence: tj-ahmad@wiu.edu; venkichem123@rediffmail.com ${ }^{4}$ Department of Chemistry, Western Illinois University, Macomb, IL 61455, USA 'Department of Chemistry, Yuvaraja's College, University of Mysore, Mysore-570005, India

Full list of author information is available at the end of the article
}

such as hydrochlorothiazide (Carlucci et al. 2000; Erk 2001). The LC-MS-MS method works for LOS in the presence of its degradation products and in plasma (Yeung et al. 2000; Gonzalez et al. 2002).

The separation science plays a key role in pharmaceutical industry ranging from impurity profiling to the final assay for monitoring the finished products. The batch assay of the pharmaceuticals in a quality control setup needs to be rapid, accurate, and sensitive. The fast quality monitoring of the products using ultra-performance liquid chromatography (UPLC) is gaining pronounced interest. Known for its advanced technology, UPLC is based on the principles of liquid chromatography, which utilizes $1.7-\mu \mathrm{m}$ column particles. This enhances the separation process without affecting the resolutions. Due to small particle size, the system entails the use of high pressure of the order 15,000 psi to pump the mobile phase. The elevated mobile phase linear velocity results in high resolution, sensitivity, and shorter analysis time. Owing to its speed and sensitivity, this technique is gaining considerable attention 


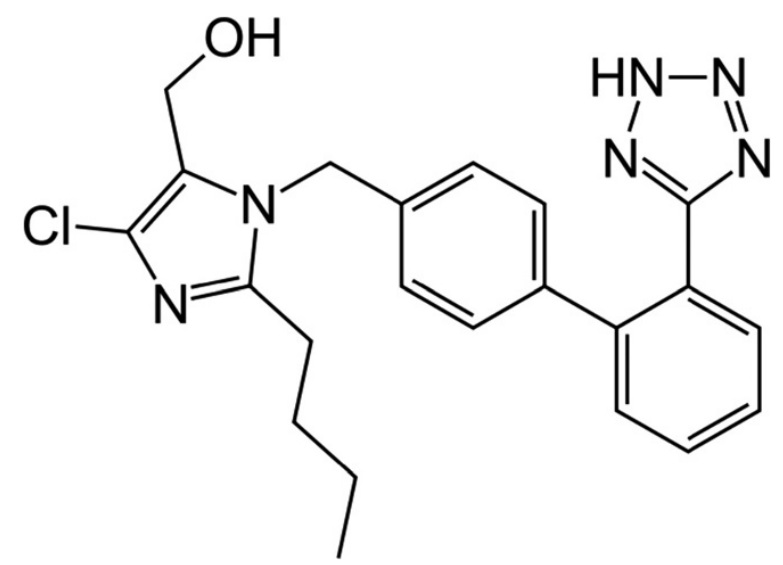

Figure 1 Molecular structure of the drug, LOS.

in recent years in different fields of pharmaceutical and biomedical analysis (Krishnaiah et al. 2010; Waren and Tchlitcheff 2006). The literature survey shows that, despite these advantages, the UPLC has not been applied for the assay of the drug, LOS.

The aim of this study is to develop and validate, according to the current $\mathrm{ICH}$ guidelines, a fast, accurate, precise, and sensitive UPLC method for the analysis of LOS in tablets without the interference from inactive ingredients.

\section{Methods}

\section{Materials and reagents}

The pure active ingredient sample of LOS was given as a gift by Jubilant Life Sciences, Mysore, India. Tablet formulations, viz. Cosart from Cipla, and Covance from Ranbaxy, were purchased from local commercial sources. Solvents such as methanol and acetonitrile (HPLC grade), potassium dihydrogen orthophosphate, and orthophosphoric acid (Qualigens, Mumbai, India) were purchased from Merck \& Co., Inc., Whitehouse Station, NJ, USA. Doubledistilled water was used throughout the investigation.

\section{Chromatographic conditions and equipment}

Analyses were carried out on a Waters Acquity UPLC (LabX, Midland, ON, Canada) with a tunable UV detector. The output signal was monitored and processed using an Empower software. The chromatographic column used was Waters Acquity UPLC BEH C18 $(100 \mathrm{~mm} \times 2.1 \mathrm{~mm}$ with $1.7-\mu \mathrm{m}$ particle size). The isocratic elution process was adopted throughout the analysis.

\section{Mobile phase preparation}

An aqueous phosphate buffer solution was prepared by dissolving $2.000 \mathrm{~g}$ of potassium dihydrogen orthophosphate in approximately $400 \mathrm{~mL}$ of water. The $\mathrm{pH}$ of this solution was adjusted to 3.2 with $10 \%$ phosphoric acid before diluting to a final volume of $500.0 \mathrm{~mL}$. A mixture of $500.0 \mathrm{~mL}$ phosphate buffer and $500.0 \mathrm{~mL}$ acetonitrile was stirred and filtered using a $0.22-\mu \mathrm{m}$ nylon membrane filter. This solution was also used as the solvent in all the subsequent preparations of analyte samples.

\section{Instrumental parameters}

The isocratic flow rate of the mobile phase was maintained at $0.20 \mathrm{~mL} \mathrm{~min} \mathrm{~m}^{-1}$. The column temperature was adjusted to $40^{\circ} \mathrm{C}$. The injection volume was $4.0 \mu \mathrm{L}$. The elution was monitored at $220 \mathrm{~nm}$ and the total run time was $5.0 \mathrm{~min}$.

\section{Preparation of stock solution}

A standard stock solution of LOS $\left(100 \mu \mathrm{g} \mathrm{mL}^{-1}\right)$ was prepared by dissolving an accurately weighed amount (5.0 $\mathrm{mg}$ ) of the drug in the solvent to a final volume of $50.0 \mathrm{~mL}$ in a volumetric flask.

\section{Procedures}

Procedure for calibration curve

Working standard solutions containing 2.0 to $15.0 \mu \mathrm{g} \mathrm{mL}$ of LOS were prepared by serial dilutions of the stock solution $\left(100 \mu \mathrm{g} \mathrm{mL}^{-1}\right)$. Aliquots of $4.0 \mu \mathrm{L}$ were injected (six injections) and eluted with the mobile phase under the reported chromatographic conditions. The average peak area vs. concentration of LOS (in $\mu \mathrm{g} \mathrm{mL}^{-1}$ ) was plotted to obtain the standard curve for determining the unknown concentrations of the analyte. Alternatively, the corresponding regression equation was derived using mean peak areaconcentration data, and the concentration of the unknown analyte can be computed from the regression equation.

\section{Preparation of tablet extracts and assay procedure}

Ten tablets (approximately 25-mg LOS each) were weighed and ground to a fine powder. A quantity equivalent to a tablet was weighed and transferred into a $100-\mathrm{mL}$ flask, dissolved in $60 \mathrm{~mL}$ of the mobile phase, sonicated for $20 \mathrm{~min}$, and then diluted to the final volume with the same mobile phase to yield a concentration of $250 \mu \mathrm{g} \mathrm{mL}{ }^{-1}$. The solution was passed through a $0.22-\mu$ m nylon membrane filter. Appropriate volumes of the filtered solution were diluted with the mobile phase to obtain the desired concentrations such as $5.0 \mathrm{ppm}$.

\section{Procedure for method validation}

Accuracy and precision To determine the accuracy and intraday precision, pure LOS solutions of three different concentrations were analyzed in six replicates each during the same day. Mobile phase was injected as the blank solution before the sample injection, and the relative standard deviation (\%RSD) values of the peak area and retention time were determined.

Limits of detection and quantification The limit of detection (LOD) and limit of quantification (LOQ) were determined by the signal-to-noise $(\mathrm{S} / \mathrm{N})$ ratio method. 


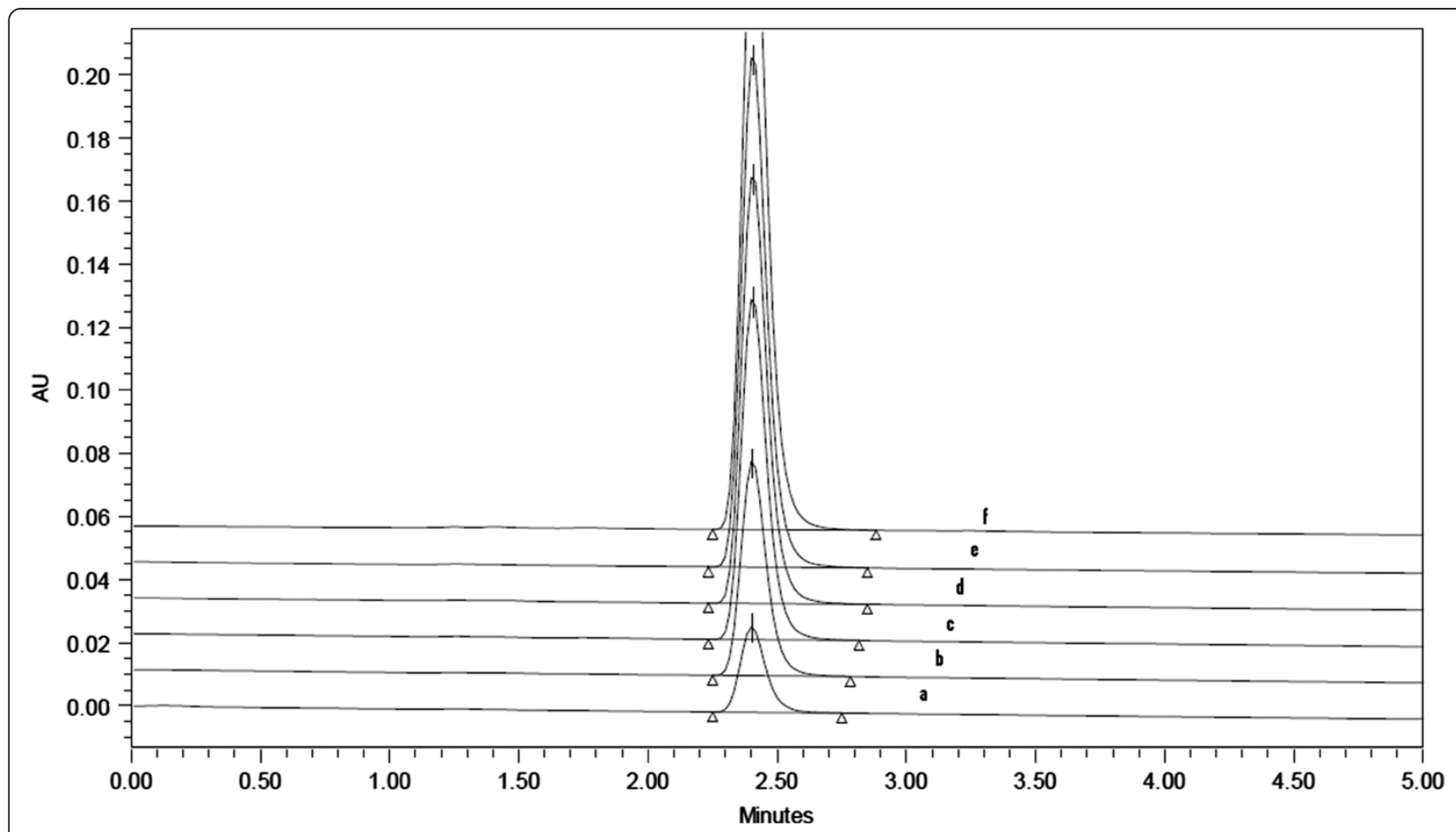

Figure 2 Overlay of chromatograms for losartan with concentrations (a) $2 \mu \mathrm{g} \mathrm{mL}^{-1}$, (b) $5 \mu \mathrm{g} \mathrm{mL}^{-1}$, (c) $8 \mu \mathrm{g} \mathrm{m} \mathrm{L}^{-1}$, (d) $10 \mu \mathrm{g} \mathrm{mL}$, (e) $12 \mu \mathrm{g} \mathrm{mL}-1$, and (f) $15 \mu \mathrm{g} \mathrm{mL}$.

These were obtained by a series of dilutions of the LOS stock solution. Precision study was performed at the LOQ level also. LOQ solution was injected six times $(n=$ 6) and the \%RSD values for the obtained peak area and retention time were calculated.

Solution and mobile phase stability The stability of the LOS solution was tested by injecting the sample into the $\mathrm{C}-18$ column. The peak area was recorded at time intervals of $0,3,6,8,12$, and $15 \mathrm{~h}$, and the RSD and time values were calculated. The mobile phase stability was studied by injecting a freshly prepared sample solution at

Table 1 Regression and sensitivity parameters for UPLC analysis of LOS

\begin{tabular}{ll}
\hline Parameter & Value \\
\hline Linearity range, $\mu \mathrm{g} \mathrm{mL^{-1 }}$ & 2.0 to 15.0 \\
Slope $(b)$ & 95,938 \\
Intercept $(a)$ & $-3,271.6$ \\
Standard deviation of intercept $\left(S_{a}\right)$ & $\pm 5,726.3$ \\
Standard deviation of slope $\left(S_{b}\right)$ & \pm 591.7 \\
Correlation co-efficient $(r)$ & 0.9999 \\
Limit of detection $(\mathrm{LOD}), \mu \mathrm{g} \mathrm{mL}^{-1}$ & 0.0543 \\
Limit of quantification $(\mathrm{LOQ}), \mu \mathrm{g} \mathrm{mL}$ & 0.018 \\
$\pm t S_{a} / \sqrt{n}$ & $4,581.7$ \\
$\pm t S_{b} / \sqrt{n}$ & 473.4 \\
\hline
\end{tabular}

the same time periods, and the RSD values of the peak areas were calculated. The RSD values of both studies were found to be less than $3.0 \%$ exhibiting compatibility of the diluent and the stability of the mobile phase.

\section{Results and discussion Method development}

The drug LOS is a basic due to the presence of imidazole and tetrazole moieties in the molecule (Figure 1). The log $P$ value of LOS was found to be 2.25 by ChemDraw Ultra Version 7.0 indicating a high lipophilicity. Acidic mobile phase with a buffer of $\mathrm{pH} 3.2$ was chosen to protonate nitrogen atoms for a fast elution. In order to achieve better efficiency of the chromatographic system, the experimental conditions such as composition and $\mathrm{pH}$ of the mobile phase, detection wavelength, nature of column, and column temperature were optimized by varying one parameter at a time while keeping the other conditions constant. Several proportions of buffer, water-acetonitrile mixture, and methanol were evaluated to obtain suitable composition of the mobile phase. Parameters such as the retention time, peak shape, theoretical plates, and run time were the major tasks while developing the method. Several combinations of gradient methods were also performed. Isocratic method was found to be better for the assay. Finally, at the mobile phase composition described under the 'Methods' section, the method gave the lowest peak tailing factor and the highest theoretical plate count. 


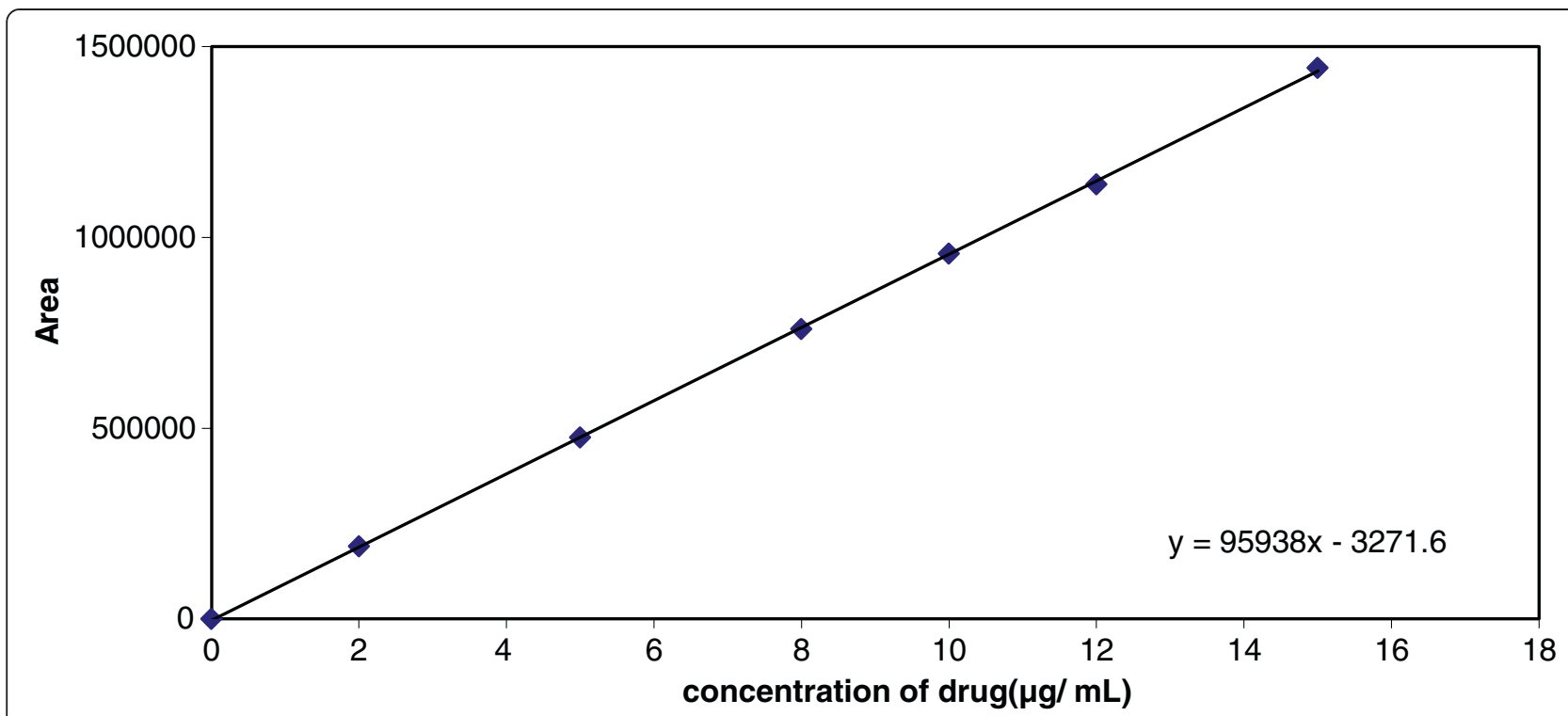

Figure 3 Linear calibration plot of peak area vs. LOS concentration.

Validation of the method

The described method for the assay of LOS has been validated as per the current ICH Q2 (R1) guidelines.

\section{Analytical parameters}

Figure 2 shows an overlay of the chromatographic peaks for LOS at different concentrations. A linear correlation was obtained between the peak area and the concentrations in the range 2.00 to $15.0 \mu \mathrm{g} \mathrm{mL}^{-1} \mathrm{LOS}$, from which the linear regression equation was computed to be $A=$ 96,192.3C - 3,271.6 $(r=0.9999)$, where $A$ is the peak area and $C$ is the concentration of LOS (in $\mu \mathrm{g} \mathrm{mL}^{-1}$ ). The LOD and LOQ values, slope, $y$-intercept, and their standard deviations evaluated are presented in Table 1 and Figure 3. These results confirm the existence of a linear relationship between the concentrations of LOS and the peak areas along with the sensitivity of the method.

\section{Accuracy and precision}

Table 2 shows the data for three concentration levels of the analyte LOS in tablets determined with and without the standard addition of an equal amount of the pure LOS. The data include method accuracy and precision represented by the relative error (RE) and RSD, respectively, for six determinations at each concentration level. Both RE and RSD decrease with the increase in the sample size showing the lowest values for the $8 \mu \mathrm{g} \mathrm{mL} L^{-1}$ sample size. However, the relatively low \%RSDs indicate the high precision of the method.

\section{Robustness of the method and stability of the solution}

The robustness of an analytical procedure is a measure of its capacity to remain unaffected by small but deliberate variations made in method parameters. It provides an indication of its reliability during normal usage. At varied chromatographic conditions (flow rate, temperature, and

Table 2 Results of determination of LOS in tablets and in standard samples

\begin{tabular}{|c|c|c|c|c|c|c|}
\hline Tablet brand name $^{a}$ & Nominal amount (mg) & LOS in tablet $\left(\mu \mathrm{g} \mathrm{mL}^{-1}\right)$ & Pure LOS added $\left(\mu \mathrm{g} \mathrm{mL}^{-1}\right)$ & Total area & \%RE & \%RSD \\
\hline \multirow[t]{9}{*}{ Covance } & 25.0 & 2.0 & 2.0 & 380,159 & -22.0 & 0.078 \\
\hline & & & & 380,892 & & \\
\hline & & & & 380,532 & & \\
\hline & & 5.0 & 5.0 & 663,598 & -9.14 & 0.033 \\
\hline & & & & 663,259 & & \\
\hline & & & & 663,124 & & \\
\hline & & 8.0 & 8.0 & 949,892 & -2.60 & 0.022 \\
\hline & & & & 950,129 & & \\
\hline & & & & 950,321 & & \\
\hline
\end{tabular}


Table 3 Robustness of the analytical method

\begin{tabular}{|c|c|c|c|c|c|}
\hline & Value & & & & \\
\hline \multirow{7}{*}{$\begin{array}{l}\text { Column temperature, 15-ppm } \\
\text { LOS }\end{array}$} & $39^{\circ} \mathrm{C}$, area & $40^{\circ} \mathrm{C}$, area & $41^{\circ} \mathrm{C}$, area & $\%$ RE & $\%$ RSD \\
\hline & $1,672,455$ & $1,675,725$ & $1,674,952$ & \multirow[t]{6}{*}{-0.097 for $39^{\circ} \mathrm{C}-0.095$ for $41^{\circ} \mathrm{C}$} & \multirow[t]{6}{*}{0.13 for $39^{\circ} \mathrm{C} 0.12$ for $41^{\circ} \mathrm{C}$} \\
\hline & $1,671,846$ & $1,672,374$ & $1,671,854$ & & \\
\hline & $1,674,985$ & $1,671,377$ & $1,671,853$ & & \\
\hline & $1,673,917$ & $1,671,377$ & $1,670,988$ & & \\
\hline & $1,674,992$ & $1,671,377$ & $1,669,852$ & & \\
\hline & $1,677,866$ & $1,669,455$ & $1,673,479$ & & \\
\hline \multirow[t]{7}{*}{ Wavelength, 15-ppm LOS } & $\begin{array}{l}243 \mathrm{~nm}, \\
\text { area }\end{array}$ & $\begin{array}{l}245 \mathrm{~nm}, \\
\text { area }\end{array}$ & $\begin{array}{l}247 \mathrm{~nm}, \\
\text { area }\end{array}$ & $\%$ RE & $\%$ RSD \\
\hline & $1,672,379$ & $1,675,725$ & $1,672,874$ & \multirow{6}{*}{$\begin{array}{l}-0.093 \text { for } 241 \mathrm{~nm}-0.090 \text { for } \\
245 \mathrm{~nm}\end{array}$} & \multirow{6}{*}{$\begin{array}{l}0.13 \text { for } 241 \mathrm{~nm} 0.06 \text { for } \\
245 \mathrm{~nm}\end{array}$} \\
\hline & $1,671,895$ & $1,672,374$ & $1,671,893$ & & \\
\hline & $1,674,813$ & $1,671,377$ & $1,671,623$ & & \\
\hline & $1,673,739$ & $1,671,898$ & $1,672,098$ & & \\
\hline & $1,674,385$ & $1,670,491$ & $1,671,254$ & & \\
\hline & $1,677,930$ & $1,669,455$ & $1,669,695$ & & \\
\hline
\end{tabular}

mobile phase composition, absorption wavelength of the detector, etc.), the analyte peak \%RSD, tailing factor, and theoretical plate count should remain close to the actual values. The RSD values ranging from $0.06 \%$ to $0.13 \%$ represent the robustness of the proposed system. Results of RE and RSD determined for the variation of temperature and absorption wavelength are presented in Table 3. At a specified time interval, values of \%RSD for the peak areas obtained for the stabilities of the drug solution and the mobile phase were within $1 \%$. This shows that there is no significant change in the elution of the peak and its system suitability criteria (\%RSD, tailing factor, theoretical plate count). The results also confirm that the standard drug solution in the mobile phase was stable at least for $15 \mathrm{~h}$ during the assay performance. The constant peak area for different time intervals is shown in Figure 4.

\section{Selectivity}

Selectivity of the method was evaluated by injecting the mobile phase, standard drug solution, and tablet extract.

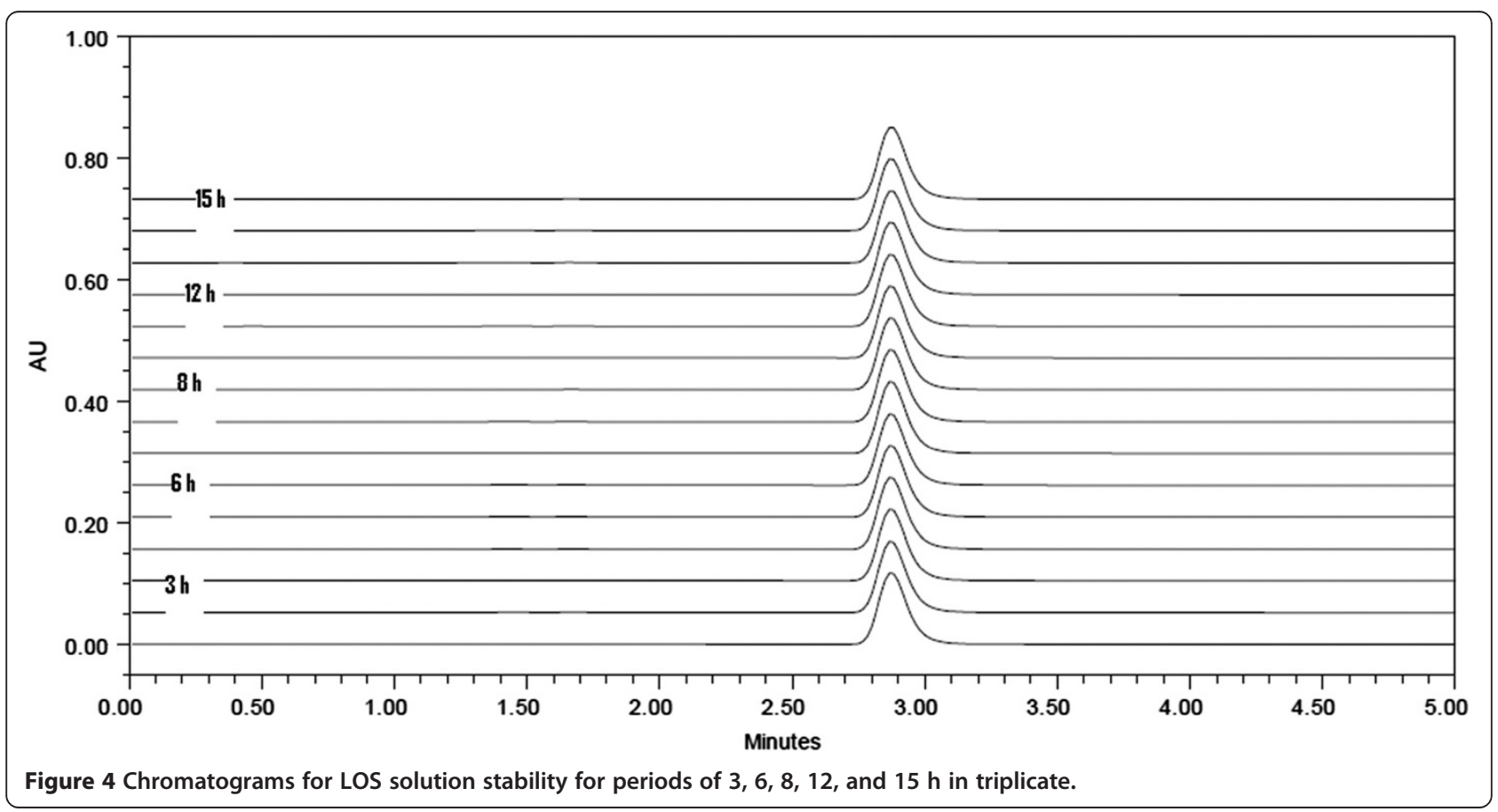


Under the experimental conditions, there was only a single peak for the drug (LOS) elusion, which showed a high selectivity of the method.

\section{Application to tablet}

Aliquots containing $250 \mu \mathrm{g} \mathrm{mL} \mathrm{m}^{-1}$ of LOS in extract and the pure drug solution were separately injected in triplicate to the UPLC system. The mean peak area of the tablets was found to be equivalent to that of the pure drug used as a positive control at the same concentration level.

\section{Recovery study}

A standard addition procedure was used to evaluate the accuracy and precision of the method. The solutions were prepared by spiking the pure LOS solution into a pre-analyzed LOS tablet extract at three different concentration levels followed by injection into the chromatographic column. The relatively low values of $\% \mathrm{RE}$ and \%RSD show high accuracy and precision of the developed UPLC method for the drug, LOS.

\section{Conclusions}

A rapid, isocratic reverse-phase ultra-performance liquid chromatographic (RP-UPLC) method was developed for the quantitative analysis of the drug, losartan potassium or LOS, in pharmaceutical dosage formulations. This method is precise, accurate, robust, and specific. Satisfactory results were obtained from the validation of the method. The short retention time obtained $(2.40 \mathrm{~min})$ enables rapid determination of LOS, which is important for its routine analysis in quality control. The method exhibits an excellent performance in terms of sensitivity and speed. Each experiment was repeated three times. Recovery of known amounts of the added analyte was calculated and is presented in Table 2. The reported values of the recovery are the average of three experiments.

\section{Competing interests}

The author declares no competing interests.

\section{Author details}

'Department of Chemistry, Yuvaraja's College, University of Mysore, Mysore-570005, India. 'Department of Chemistry, Government First Grade College, K.R. Nagar, Mysore, India. ${ }^{3}$ Department of studies in Chemistry, University of Mysore, Manasagangothri, Mysore, India. ${ }^{4}$ Department of Chemistry, Western Illinois University, Macomb, IL 61455, USA.

Received: 16 August 2013 Accepted: 4 April 2014

$$
\text { 1. } 1 \text { - } 1 \text {. }
$$

\section{References}

Carlucci G, Palumbo G, Mazzeo P, Quaglia MG (2000) Simultaneous determination of losartan and hydrochlorothiazide in tablets by highperformance liquid chromatography. J Pharm Biomed Anal 23:185-189

Conlin PR (2001) Efficacy and safety of angiotensin receptor blockers: a review of losartan in essential hypertension. Curr Ther Res Clin Exp 62:673-673

Erk N (2001) Analysis of binary mixtures of losartan potassium and hydrochlorothiazide by using high performance liquid chromatography, ratio derivative spectrophotometric and compensation technique. J Pharm Biomed Anal 24:603-611
Gonzalez L, Lopez JA, Alonso RM, Jimenez RM (2002) Fast screening method for the determination of angiotensin II receptor antagonists in human plasma by high-performance liquid chromatography with fluorimetric detection. J Chromatogr A 949:49-60

Krishnaiah C, Reddy AR, Kumar R, Mukkanti K (2010) Stability-indicating UPLC method for determination of Valsartan and their degradation products in active pharmaceutical ingredient and pharmaceutical dosage forms. J Pharm Biomed Anal 53:483-489

Pedroso CF, de Oliveira JG, Campos FR, Gonzalves AG, Trindade CLB, Pontarolo R (2009) A Validated RP-LC Method for Simultaneous Determination of Losartan Potassium and Amlodipine Besilate in Pharmaceutical Preparations. Chromatographia 69:S201-S206

Seburg RA, Ballard JM, Hwang TL, Sullivan CM (2006) Photosensitized degradation of losartan potassium in an extemporaneous suspension formulation. J Pharm Biomed Anal 42:411-422

Waren SAC, Tchlitcheff P (2006) Use of ultra-performance liquid chromatography in pharmaceutical development. J Chromatogr A 1119:140-146

Yeung PK, Jamieson A, Smith GJ, Fice D, Pollak PT (2000) Determination of plasma concentrations of losartan in patients by HPLC using solid phase extraction and UV detection. Int J Pharm 204:17-22

doi:10.1186/s40543-014-0033-2

Cite this article as: Ahmad et al:: Rapid ultra-performance liquid chromatography assay of losartan potassium in bulk and formulations. Journal of Analytical Science and Technology 2014 5:33.

\section{Submit your manuscript to a SpringerOpen ${ }^{\circ}$ journal and benefit from:}

- Convenient online submission

- Rigorous peer review

- Immediate publication on acceptance

- Open access: articles freely available online

- High visibility within the field

- Retaining the copyright to your article

Submit your next manuscript at $>$ springeropen.com 